\title{
Multistate Markov model for predicting the natural disease progression of type 2 diabetes based on hemoglobin A1c
}

\author{
Komal Goel $^{{ }^{*} \oplus}$, Gurprit Grover ${ }^{2}$, Ankita Sharma ${ }^{1}$, Sejong Bae ${ }^{3}$ \\ ${ }^{1}$ Department of Statistics and, Faculty of Mathematical Sciences, University of Delhi, India \\ ${ }^{2}$ Department of Statistics, Faculty of Mathematical Sciences, University of Delhi, India \\ ${ }^{3}$ Division of Preventive Medicine, University Alabama School of Medicine, Alabama, USA
}

\section{A R T I C L E I N F 0}

Article Type:

Original

\section{Article History:}

Received: 20 August 2018

Accepted: 17 October 2018

ePublished: 3 December 2018

\section{Keywords:}

Glycated hemoglobin

Multistate Markov model

Type 2 diabetes

Type 1 diabetes mellitus

\begin{abstract}
A B S T R A C T
Introduction: Type 2 diabetes is a common non-communicable disease, especially in developing countries like India, posing a huge economic burden on the family and nation as a whole. It is a chronic metabolic disorder in which prevalence has been increasing steadily all over the world. In studies of many chronic medical conditions, the health status of a patient may be characterized using a finite number of disease states. The multi-state Markov model is a useful way to describe states of a disease over time. In this research article, we have illustrated the usefulness of multistate Markov models in the analysis of follow-up of diabetes. The valuable information provided by the hemoglobin Alc (HbAlc) test has rendered it as a reliable biomarker for the diagnosis and prognosis of diabetes.

Objectives: The main purpose of this study is to assess the importance and significance of HbAlc as a useful disease marker for type 2 diabetes by using a three-state Markov model.

Patients and Methods: A total of 246 type 2 diabetic patients were included in this study. These patients are classified in different states on the basis of their available baseline value of HbAlc. HbAlc repeated after every 1 year for consecutive four years. Based on ranges of HbAlc, three transient states $(4 \leq \mathrm{HbAlC}$ $\leq 5.6,5.7 \leq \mathrm{HbAlC} \leq 6.4$ and $\mathrm{HbAlC} \geq 6.5 \%$ ) have been defined. Additionally, transition intensities, transition probabilities, mean sojourn time in each state and also expected state specific survival time have been assessed. All the statistical analysis has been performed using the msm package in R software. Results: The mean age of patients at diagnosis was 26.12 years $(\mathrm{SD}=7.60)$, ranging from 10 to 49 years. The estimates of transition intensities reveal that a patient in state 1 is $16.4(0.82 / 0.05)$ times more likely to move to state 2 than to move to diabetic state. Similarly, a patient in pre-diabetic is $7.5(2.34 / 0.31)$ times more likely to move to diabetic state as compared to normal state. Additionally, once a patient is in a diabetic state there is $79 \%$ chances of remaining in a diabetic state as compared to $4 \%$ and $17 \%$ of moving to normal or pre-diabetic state, this implies that a patient who once in the diabetic state is difficult to move to a normal or pre-diabetic state.

Conclusion: The estimated total length of time spent in each state is forecasted to be four months in normal state, five months in pre-diabetic state and 39 months in diabetic state. Hence, it has been concluded that, once the patient enters the diabetic state $(\mathrm{HbAlc}>6.4)$, the chances of getting back to normal or pre-diabetic state are very small.
\end{abstract}

Implication for health policy/practice/research/medical education:

Once the patient enters the diabetic state $(\mathrm{HbAlc}>6.4 \%)$, the chances of getting back to normal or pre-diabetic state are very small.

Please cite this paper as: Goel K, Grover G, Sharma A, Bae S. Multistate Markov model for predicting the natural disease progression of type 2 diabetes based on hemoglobin A1c. J Nephropharmacol. 2019;8(1):e04. DOI: 10.15171/npj.2019.04

\section{Introduction}

Diabetes mellitus (DM) is one of the most common noncommunicable diseases globally. It is a chronic metabolic disorder characterized by hyperglycemia, either because the body does not produce enough insulin, or because cells do not respond to the insulin that is produced. Diabetes is a global endemic with rapidly increasing prevalence in both developing and developed countries. According, to the 2014 release of the American Diabetes Association (ADA), as of 2012, 29.1 million Americans, or 9.3\% of 
the total US population, had diabetes. The worldwide prevalence of diabetes in 2000 was approximately $2.8 \%$ and is estimated to grow to $4.4 \%$ by 2030 (1). Basically, diabetes is a group of metabolic disorders in which there are high blood sugar levels over a prolonged period. Symptoms of high blood sugar include frequent urination, increased thirst, and increased hunger. It can cause many complications, if left untreated. Of all the cases of DM, almost $90 \%$ are of type $2 \mathrm{DM}$ (T2DM) and rest being type 1 DM (T1DM). T1DM accounts for only about 5\%$10 \%$ of all cases of diabetes. T2DM is a common noncommunicable disease, especially in developing countries like India, posing a huge economic burden on the family and nation as a whole. It is a chronic metabolic disorder in which prevalence has been increasing steadily all over the world. As a result of this trend, it is fast becoming an epidemic in some countries of the world with the number of people affected expected to double in the next decade due to increase in ageing population, thereby adding to the already existing burden for healthcare providers, especially in poorly developed countries (2). Worldwide the prevalence of T2DM has been rising, and more than 180 million people are affected globally. The noteworthy fact is that epidemics of DM have taken place in developing countries (3). It is predicted that the prevalence of DM in adults of which T2DM is becoming prominent will increase in the next two decades and much of the increase will occur in developing countries where the majority of patients are aged between 45 and 64 years. The major global diabetic load occurs in India and China, where more than $75 \%$ of diabetic subjects will live by the year 2025 (4) and by then every fifth diabetic subjects in the world would be an Indian (5). People living with T2DM are more vulnerable to various forms of both short- and long-term complications, which often lead to their premature death. This tendency of increased morbidity and mortality is seen in patients with T2DM because of the commonness of this T2DM, its insidious onset and late recognition.

Ever since diabetes was recognized, plasma glucose became the criteria for the diagnosis of diabetes. It was either the fasting plasma glucose (FPG), or the 2-hour value in the 75-g oral glucose tolerance test (OGTT). Gradually, HbA1c came into the picture and its potentiality was recognized by WHO in 1985 in diabetic management and sugar monitoring. However, in 2009, when an International Expert Committee that included representatives of the $\mathrm{ADA}$, the International Diabetes Federation (IDF), and the European Association for the Study of Diabetes (EASD) recommended the use of the A1c test to diagnose diabetes, with a threshold of $\geq 6.5 \%$. All the three parameters possess their own characteristic pros and cons regarding their utility for diagnosis of diabetes. Glycated hemoglobin is noteworthy because it can be used for both diagnosis of T2DM (bearing some exception), as well as in prognosis. This article tries to discuss the significance of glycated hemoglobin (HbAlc) as a disease marker in the diagnosis of diabetes using multistate Markov models. Glycated hemoglobin gives an estimate of long-term average glycemic status. It is used routinely to assess glycemic control in diabetics to attain treatment goals and prevent long term complications. Its recommendation for diagnosis of DM has evoked mixed response worldwide. ADA has recommended that $\mathrm{HbA1c}$ is a possible substitute to fasting blood glucose for diagnosis of diabetes. The valuable information provided by a single $\mathrm{HbAlc}$ test has rendered it as a reliable biomarker for the diagnosis and prognosis of diabetes. It is an important indicator of long-term glycemic control with the ability to reflect the cumulative glycemic history of the preceding 2 to 3 months.

Historically, HbA1c was first isolated by (6) in 1958 and characterized by (7) in 1968, as a glycoprotein. The elevated levels of HbA1c in diabetic patients were reported by (8) in 1969. Bunn et al (9) identified the pathway leading to the formation of HbAlc in 1975. Sherwani et al (10) concluded HbAlc as a reliable biomarker for the diagnosis and prognosis of diabetes.

In studies of many chronic medical conditions, the health status of a patient may be characterized using a finite number of disease states. When patients are observed over time, the dynamic nature of the disease process may then be examined by modeling the rates at which patients make transitions among these states. A wide range of situations like, HIV/AIDS (11-14), breast cancer $(15,16)$, dementia (17), diabetic retinopathy $(18,19)$, and liver cirrhosis $(20,21)$ had presented the use of multistate Markov models to assess the dependence of risk of death on marker level or disease state. Marshall et al (18) discussed the application of a multi-state model (MSM) to diabetic retinopathy under the assumption that a continuous time Markov process determines the transition times between disease stages (18). Begun et al (22) has developed a nine-state continuous-time Markov chain model for quantifying disease progression and the time-dependent influence of relevant risk factors for diabetic foot patients and then tested this model on real world data. To the best of our knowledge, no study has been conducted for evaluating the disease progression of type 2 diabetes using HbAlc as a disease marker in multistate Markov model.

\section{Objectives}

In this research article, we have tried to develop a three state Markov model based on the ranges of glycated hemoglobin (HbAlc) for predicting the disease progression of type 2 diabetic patients. Additionally, the estimates of the transition intensities and probabilities between various states have been obtained.

\section{Patients and Methods \\ Study design}

The study population includes all type 2 diabetic cancer 
patients of Young Diabetes Registry (YDR) of the All India Institute of Medical sciences (AIIMS). This registry recruited all cases of diabetes reporting on/after January 1,2000 , with the age equal to or less than 25 years at the time of diagnosis of diabetes (defined as FPG $\geq 126 \mathrm{mg}$ / $\mathrm{dL}$ and/or 2 hours post-load plasma glucose $\geq 200 \mathrm{mg} / \mathrm{dL}$ ) and residing within the assigned geographical area. Both previously treated and untreated cases were included. Data from the period 2000-2006 were collected retrospectively in a structured format from medical records. The followup data of individuals registered in YDR was captured annually using an annual follow-up proforma. The information on demographic, socioeconomic, clinical, and phenotypic profile of participants at registration and follow-up were recorded. Anthropometric measurements were done at the respective reporting centers using standardized instruments.

\section{Multi-state Markov model}

MSM is a model for a continuous time stochastic process allowing individuals to move among a finite number of states. In this analysis, the three states of disease progression of diabetic patients are defined based on the established ranges of $\mathrm{HbAlc}$. The three reversible transient states are defined as follows; state $1 ; 4 \leq \mathrm{HbA} 1 \mathrm{C}$ $\leq 5.6 \%$, state $2 ; 5.7 \leq \mathrm{HbA} 1 \mathrm{C} \leq 6.4 \%$; and state 3 ; $\mathrm{HbA} 1 \mathrm{C}$ $\geq 6.5 \%$. The schematic representation of the proposed model is shown in Figure 1. The possible transitions along with intensities have been illustrated in the diagram.

More formally, let us suppose that there are $\mathrm{n}$ diabetic patients under study, and a patient may move in the three state Markov model with discrete state space $S=\{1,2,3\}$, where 1,2 and 3 are the transient states. If $X(t)=r$ be the state of a patient at any time $t$, then the intensity with which the patient moves to state $s$ during the interval ( $t$, $\mathrm{t}+\Delta t)$ is defined as

$\lambda_{r s}(t)=\lim _{\Delta t \rightarrow 0} \frac{P(X(t+\Delta t)=s / X(t)=r)}{\Delta t}$ for $\mathrm{r}, \mathrm{s}=1,2,3$

The transition intensity matrix, defined as $\mathrm{P}=\left(\lambda_{r s}\right)_{3 \times 3}$, has the following properties:

(i) $\sum_{s \in S} \lambda_{r s}=0$ for all $\mathrm{r}$,

(ii) $\lambda_{r r}=-\sum_{r \neq s} \lambda_{r s}$ for all $\mathrm{r}$.

Where, $\lambda_{i s}$ 's are the transition intensities, and the corresponding 3-states transition probability matrix can be defined as:

$P=\left(\begin{array}{lll}P_{11} & P_{12} & P_{13} \\ P_{21} & P_{22} & P_{23} \\ P_{31} & P_{32} & P_{33}\end{array}\right)$

Where $P_{11}, P_{12}, P_{13}, P_{21}, P_{22}, P_{23}, P_{31}, P_{32}$ and $P_{33}$ are the illness transition probabilities which can be calculated as:
$P_{11}(0, t)=$ Pr. [that an individual in state 1 at time 0 will be in same state at time $\mathrm{t}$ ]

$$
\begin{aligned}
& =\exp \left[\int_{0}^{t} \lambda_{11} d u\right] \\
& =\exp \left[\lambda_{11} t\right]
\end{aligned}
$$

$P_{12}(0, t)=\operatorname{Pr}$. [that an individual in state 1 at time 0 will be in state 2 at time $\mathrm{t}$ ]

$=\int_{0}^{t} \exp \left[\int_{0}^{t_{1}} \lambda_{11} d u\right] \lambda_{12} \exp \left[\int_{t_{1}}^{t} \lambda_{22} d v\right] d t_{1}$

$=\int_{0}^{t} \exp \left(\lambda_{11} t_{1}\right) \lambda_{12} \exp \left[\lambda_{22}\left(t-t_{1}\right)\right] d t_{1}$

$=\lambda_{12} e^{\lambda_{22} t} \int_{0}^{t} \exp \left[\left(\lambda_{11}-\lambda_{22}\right) t_{1}\right] d t_{1}$

$=\frac{\lambda_{12}}{\lambda_{11}-\lambda_{22}}\left[\exp \left(\lambda_{11} t\right)-\exp \left(\lambda_{22} t\right)\right]$

$P_{13}(0, t)=\operatorname{Pr}$. [that an individual in state 1 at time 0 will be in state 3 at time $\mathrm{t}$ ]

$$
\begin{aligned}
& =\int_{0}^{t} \exp \left[\int_{0}^{t_{1}} \lambda_{11} d u\right] \lambda_{13} \exp \left[\int_{t_{1}}^{t} \lambda_{33} d v\right] d t_{1} \\
& =\int_{0}^{t} \exp \left(\lambda_{11} t_{1}\right) \lambda_{13} \exp \left[\lambda_{33}\left(t-t_{1}\right)\right] d t_{1} \\
& =\lambda_{13} e^{\lambda_{33} t} \int_{n}^{t} \exp \left[\left(\lambda_{11}-\lambda_{33}\right) t_{1}\right] d t_{1} \\
& =\frac{\lambda_{13}}{\lambda_{11}-\lambda_{33}}\left[\exp \left(\lambda_{11} t\right)-\exp \left(\lambda_{33} t\right)\right]
\end{aligned}
$$

$P_{21}(0, t)=\operatorname{Pr}$. [that an individual in state 2 at time 0 will be in state 1 at time $\mathrm{t}$ ]

$$
\begin{aligned}
& =\int_{0}^{t} \exp \left[\int_{0}^{t_{1}} \lambda_{22} d u\right] \lambda_{21} \exp \left[\int_{t_{1}}^{t} \lambda_{11} d v\right] d t_{1} \\
& =\int_{0}^{t} \exp \left(\lambda_{22} t_{1}\right) \lambda_{21} \exp \left[\lambda_{11}\left(t-t_{1}\right)\right] d t_{1} \\
& =\lambda_{21} e^{\lambda_{11} t} \int_{0}^{t_{1}} \exp \left[\left(\lambda_{22}-\lambda_{11}\right) t_{1}\right] d t_{1} \\
& =\frac{\lambda_{21}}{\lambda_{22}-\lambda_{11}}\left[\exp \left(\lambda_{22} t\right)-\exp \left(\lambda_{11} t\right)\right]
\end{aligned}
$$

$P_{22}(0, t)=\operatorname{Pr}$. [that an individual in state 2 at time 0 will be in same state at time $\mathrm{t}$ ]

$$
\begin{aligned}
& =\exp \left[\int_{0}^{t} \lambda_{22} d u\right] \\
& =\exp \left[\lambda_{22} t\right] \\
& P_{23}(0, t)=\operatorname{Pr} \text {. [that an individual in } \\
& \text { in state } 3 \text { at time } \mathrm{t}] \\
& =\int_{0}^{t} \exp \left[\int_{0}^{t_{1}} \lambda_{22} d u\right] \lambda_{23} \exp \left[\int_{t_{1}}^{t} \lambda_{33} d v\right] d t_{1} \\
& =\int_{0}^{t} \exp \left(\lambda_{22} t_{1}\right) \lambda_{23} \exp \left[\lambda_{33}\left(t-t_{1}\right)\right] d t_{1}
\end{aligned}
$$

$P_{23}(0, t)=\operatorname{Pr}$. [that an individual in state 2 at time 0 will be 
$=\frac{\lambda_{23}}{\lambda_{22}-\lambda_{33}}\left[\exp \left(\lambda_{22} t\right)-\exp \left(\lambda_{33} t\right)\right]$

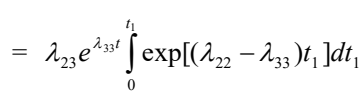

$P_{31}(0, t)=\operatorname{Pr}$. [that an individual in state 3 at time 0 will be in state 1 at time $t$ ]

$=\int_{0}^{t} \exp \left[\int_{0}^{t_{1}} \lambda_{33} d u\right] \lambda_{31} \exp \left[\int_{t_{1}}^{t} \lambda_{11} d v\right] d t_{1}$

$=\int_{0}^{t} \exp \left(\lambda_{33} t_{1}\right) \lambda_{31} \exp \left[\lambda_{11}\left(t-t_{1}\right)\right] d t_{1}$

$=\lambda_{31} e^{\lambda_{11} t} \int_{0}^{t_{1}} \exp \left[\left(\lambda_{33}-\lambda_{11}\right) t_{1}\right] d t_{1}$

$=\frac{\lambda_{31}}{\lambda_{33}-\lambda_{11}}\left[\exp \left(\lambda_{33} t\right)-\exp \left(\lambda_{11} t\right)\right]$

$P_{32}(0, t)=\operatorname{Pr}$. [that an individual in state 3 at time 0 will be in state 2 at time $\mathrm{t}$ ]

$$
\begin{aligned}
& =\int_{0}^{t} \exp \left[\int_{0}^{t_{1}} \lambda_{33} d u\right] \lambda_{32} \exp \left[\int_{t_{1}}^{t} \lambda_{22} d v\right] d t_{1} \\
& =\int_{0}^{t} \exp \left(\lambda_{33} t_{1}\right) \lambda_{32} \exp \left[\lambda_{22}\left(t-t_{1}\right)\right] d t_{1} \\
& =\lambda_{32} e^{\lambda_{22} t} \int_{0}^{t} \exp \left[\left(\lambda_{33}-\lambda_{22}\right) t_{1}\right] d t_{1} \\
& =\frac{\lambda_{32}}{\lambda_{33}-\lambda_{22}}\left[\exp \left(\lambda_{33} t\right)-\exp \left(\lambda_{22} t\right)\right]
\end{aligned}
$$

$P_{33}(0, t)=\operatorname{Pr}$. [that an individual in state 3 at time 0 will be in same state at time $\mathrm{t}]$

$$
\begin{aligned}
& =\exp \left[\int_{0}^{t} \lambda_{33} d u\right] \\
& =\exp \left[\lambda_{33} t\right]
\end{aligned}
$$

The detailed mathematical derivation and maximum likelihood estimation procedure has been given $(23,24)$. The illness transition probabilities are estimated using the msm package in $\mathrm{R}$ software.

\section{Ethical issues}

The research followed the tenets of the Declaration of Helsinki. This study was conducted as a part of the Ph.D. thesis of Ankita Sharma under the supervision of Prof. Gurprit Grover in Department of Statistics, University of Delhi.

\section{Statistical analysis}

Data on biochemical parameters were taken from the medical records. All the statistical analysis has been performed using the msm package in $\mathrm{R}$ software (25).

\section{Results}

The study population includes 246 type 2 diabetic patients, who were diagnosed during January 2000 to
December 2011. The mean age of patients at diagnosis was 26.12 years $(\mathrm{SD}=7.60)$, ranging from 10 to 49 years. The characteristics of important demographic and clinical factors are summarized in Table 1.

Table 2 shows that the observed transitions between states (rows to column) during the follow up visits. There are 5 transitions from normal to diabetic state and 14 transitions from pre-diabetic to diabetic. Initially, the Markov model without covariate has been used to study the overall disease progression. The estimates of transition intensities $\left(\lambda_{i j}\right)$ with 95\% CI are presented in Table 3. It

\begin{tabular}{|c|c|c|c|}
\hline Variable & Mean & SD & Min-Max \\
\hline Age (y) & 26.12 & 7.60 & $10-49$ \\
\hline Diabetes duration (mon) & 56.75 & 80.69 & $0-428$ \\
\hline $\begin{array}{l}\text { Post prandial plasma } \\
\text { glucose }(\mathrm{mg} / \mathrm{dl})\end{array}$ & 325.49 & 101.53 & $142-545$ \\
\hline Height (m) & 1.62 & 0.09 & $1.32-1.85$ \\
\hline Weight (kg) & 58.50 & 24.59 & $4-116.7$ \\
\hline Birth weight (kg) & 2.67 & 1.15 & $2-4$ \\
\hline Body mass index $\left(\mathrm{kg} / \mathrm{m}^{2}\right)$ & 22.92 & 8.42 & $2.2-41.86$ \\
\hline \multirow[t]{2}{*}{$\begin{array}{l}\text { Fasting blood glucose (mg/ } \\
\mathrm{dL} \text { ) }\end{array}$} & 233.16 & 74.67 & $95-455$ \\
\hline & No. (\%) & & \\
\hline \multicolumn{4}{|l|}{ Gender } \\
\hline Male & $112(45.53)$ & & \\
\hline Female & $134(54.47)$ & & \\
\hline \multicolumn{4}{|l|}{ Economic status } \\
\hline Low & $6(3.43)$ & & \\
\hline Medium & $156(89.14)$ & & \\
\hline \multirow[t]{2}{*}{ High } & $13(7.43)$ & & \\
\hline & Yes & No & \\
\hline Osmotic & $28(11.67)$ & $212(88.33)$ & \\
\hline Ketosis & $1(0.43)$ & $230(99.57)$ & \\
\hline Weight loss & 30 (12.99) & 201 (87.01) & \\
\hline Incidental diabetes & $49(21.21)$ & 182 (78.79) & \\
\hline Previous hospitalization & $182(73.98)$ & $64(26.02)$ & \\
\hline Hypoglycemia & $5(2.03)$ & 241 (97.97) & \\
\hline Sepsis & $3(1.22)$ & $243(98.78)$ & \\
\hline Diabetic ketoacidosis & $111(45.12)$ & $135(54.88)$ & \\
\hline $\begin{array}{l}\text { Any other cause of } \\
\text { hospitalization }\end{array}$ & $56(22.76)$ & $190(77.24)$ & \\
\hline Regular insulin & $202(85.23)$ & $35(14.77)$ & \\
\hline Intermediate insulin & $212(90.60)$ & $22(9.40)$ & \\
\hline Long acting analogue & $226(97.84)$ & $5(2.16)$ & \\
\hline Premixed insulin & 187 (79.91) & $47(20.09)$ & \\
\hline Short acting analogue & $231(100)$ & $0(0.00)$ & \\
\hline Premixed Analogue & $218(94.37)$ & $13(5.63)$ & \\
\hline Oral anti-diabetics & 206 (86.19) & $33(13.81)$ & \\
\hline \multicolumn{4}{|l|}{ Insulin regimen } \\
\hline Thrice a day & $7(7)$ & & \\
\hline Once a day & $22(22)$ & & \\
\hline Twice a day & $68(68)$ & & \\
\hline Multi-dose & $3(3)$ & & \\
\hline Pump & 0 & & \\
\hline
\end{tabular}
reveals that a patient in state 1 is $16.4(0.82 / 0.05)$ times more likely to move to state 2 than to move to diabetic state. Similarly, a patient in pre-diabetic is $7.5(2.34 / 0.31)$

Table 1. Demographic and clinical characteristics of type 2 diabetic patients 
Table 2. Number of observed transitions between states (rows to columns)

\begin{tabular}{lccc}
\hline States & $\begin{array}{c}\text { Normal } \\
\text { (State 1) }\end{array}$ & $\begin{array}{c}\text { Pre-diabetic } \\
\text { (State 2) }\end{array}$ & $\begin{array}{c}\text { Diabetic } \\
\text { (State 3) }\end{array}$ \\
\hline Normal (State 1) & $4(44.44)$ & $3(33.33)$ & $2(22.22)$ \\
Pre-diabetic (State 2) & $2(10.53)$ & $3(15.78)$ & $14(73.68)$ \\
Diabetic (State 3) & $3(3.89)$ & $15(19.48)$ & $59(76.62)$ \\
\hline
\end{tabular}

Table 3. Number of observed transitions between states (rows to columns)

\begin{tabular}{llll}
\hline States & Normal (State 1) & $\begin{array}{l}\text { Pre-diabetic } \\
\text { (State 2) }\end{array}$ & $\begin{array}{l}\text { Diabetic } \\
\text { (State 3) }\end{array}$ \\
\hline $\begin{array}{l}\text { Normal } \\
\text { (State 1) }\end{array}$ & $-0.88(-2.3,-0.33)$ & $0.82(0.27,2.45)$ & $0.05(0.03,8.82)$ \\
$\begin{array}{l}\text { Pre-diabetic } \\
\text { (State 2) }\end{array}$ & $0.31(0.05,1.96)$ & $-2.66(-0.65,1.06)$ & $2.34(0.88,6.23)$ \\
$\begin{array}{l}\text { Diabetic } \\
\text { (State 3) }\end{array}$ & $0.02(0.00,12.55)$ & $0.59(0.21,1.68)$ & $-0.61(-0.16,-0.22)$ \\
\hline
\end{tabular}

times more likely to move to diabetic state as compared to normal state.

The estimated transitions probabilities for one year are presented in Table 4 . It can be seen from Table 4 that a patient in normal state has a $46 \%$ chances of remaining in the same state as compared to $21 \%$ and $33 \%$ of moving to state 2 and to state 3 , respectively after a follow-up of one year. Similarly, a patient in pre-diabetic has $22 \%$ chances of remaining in the same state than $9 \%$ and $69 \%$ of moving to state 1 and state 3 respectively at end of one year. Additionally, once a patient is in a diabetic state there is a $79 \%$ chances of remaining in a diabetic state as compared to $4 \%$ and $17 \%$ of moving to normal or pre-diabetic state, this implies that a patient who once in the diabetes state is difficult to move to a normal or pre-diabetic state.

Table 5 presents the estimates of transition probabilities for a total follow-up period of 4 years which shows a significant reduction as compared to the entries of Table 4. After 4 years the chances of moving to a diabetic state from a normal or pre-diabetic state has increased to $73 \%$ as compared to $33 \%$ and $69 \%$ after one year follow-up.

Table 6 presents the mean sojourn times which describe the average period in a single stay in a state before moving to another state, which is found to be 1.14 (95\% CI: 0.43 , 2.99 ) for state $1,0.4$ (95\% CI: $0.15,0.94)$ for state 2 and 1.65 (95\% CI: $0.62,4.36)$ for state 3 . The estimated total length of time spent in each state is forecasted to be 4 months in normal state, 5 months in pre-diabetic state and 39 months in diabetic state implies that once a patient has diabetes, it is difficult to move to normal or pre-diabetic state.

\section{Discussion}

Diabetes is a global endemic with rapidly increasing prevalence in both developing and developed countries.
Table 4. Estimated 1-year transition probabilities

\begin{tabular}{lccc}
\hline States & $\begin{array}{c}\text { Normal } \\
\text { (State 1) }\end{array}$ & $\begin{array}{c}\text { Pre-diabetic } \\
\text { (State 2) }\end{array}$ & $\begin{array}{c}\text { Diabetic } \\
\text { (State 3) }\end{array}$ \\
\hline Normal (State 1) & 0.46 & 0.21 & 0.33 \\
Pre-diabetic (State 2) & 0.09 & 0.22 & 0.69 \\
Diabetic (State 3) & 0.04 & 0.17 & 0.79 \\
\hline
\end{tabular}

Table 5. Estimated 4-year transition probabilities

\begin{tabular}{lccc}
\hline States & $\begin{array}{c}\text { Normal } \\
\text { (State 1) }\end{array}$ & $\begin{array}{c}\text { Pre-diabetic } \\
\text { (State 2) }\end{array}$ & $\begin{array}{c}\text { Diabetic } \\
\text { (State 3) }\end{array}$ \\
\hline Normal (State 1) & 0.11 & 0.19 & 0.70 \\
Pre-diabetic (State 2) & 0.08 & 0.20 & 0.73 \\
Diabetic (State 3) & 0.08 & 0.19 & 0.75 \\
\hline
\end{tabular}

Table 6. Mean sojourn times with $95 \%$ confidence interval

\begin{tabular}{lcccc}
\hline States & Estimates & SE & \multicolumn{2}{c}{$95 \% \mathrm{Cl}$} \\
\hline Normal (State 1) & 1.14 & 0.56 & 0.43 & 2.99 \\
Pre-diabetic (State 2) & 0.38 & 0.17 & 0.15 & 0.94 \\
Diabetic (State 3) & 1.65 & 0.82 & 0.62 & 4.36 \\
\hline
\end{tabular}

The valuable information provided by a single $\mathrm{HbA} 1 \mathrm{c}$ test has rendered it as a reliable biomarker for the diagnosis and prognosis of diabetes. Glycosylated hemoglobin provides a reliable measure of chronic glycemia and correlates well with the risk of long-term diabetes complications, so that it is currently considered the test of choice for monitoring and chronic management of diabetes. Over the last four decades $\mathrm{HbAlc}$ has become a very important part of both diagnosis and treatment of diabetes. To add to this, there is no nationwide study published on modeling $\mathrm{HbA} 1 \mathrm{c}$ as a disease marker for type 2 diabetic patients using a multistate Markov model. This research work is one of the very few studies that analyze the importance and significance of $\mathrm{HbAlc}$ as a useful disease marker for diabetes. By exploiting the properties of Markov models, we have illustrated the usefulness of a multi stage illness model in the analysis of follow-up studies of diabetes. The main purpose of this study is to assess the impact of HbAlc (glycosylated hemoglobin) as a useful disease marker by using a multistate Markov model to estimate transition intensities and transition probabilities among various states (transient) of the diabetic patients. In this study, 246 type 2 diabetic patients were observed at the end of year one and tracked at the end of year four. We have implemented methods introduced by (23) that allow quite general models to be fitted. Various intensities and their corresponding transition probabilities have been computed for all three stages. These results have been obtained in the absence of covariates. The Markov model proposed for this study is a three-state model (normal, pre-diabetic and diabetic). 
As discussed in the results section the significant findings of our analysis are that during the follow up period of 4 years (48 months) the total estimated stay time for patients is found to be 4 months in normal state, 5 months in pre-diabetic state and 39 months in diabetic state respectively. Hence, it has been concluded that, once the patient enters the diabetic state (HbAlc $>6.4 \%)$, the chances of getting back to normal or pre-diabetic state are very small.

The results of the multistate Markov model have confirmed much of what is known about the natural course and the factors affecting the progression of diabetes. Using this type of multistate model helped us to learn more about the various factors affecting the disease process over time.

\section{Conclusion}

In this study, we concluded that, once the patient enters the diabetic state $(\mathrm{HbAlc}>6.4 \%)$, the chances of getting back to normal or pre-diabetic state are very small.

\section{Study limitations}

The small sample size and the short follow-up period are the two limitations of this study that must be acknowledged.

\section{Authors' contribution}

GG and KG designed the study, observed accuracy and validity of the study. KG collected the data and followed the study. GG and SB supervised the project. KG and AS wrote the paper. All authors edited and revised the final manuscript and accepted its publication.

\section{Conflicts of interest}

The authors declared no competing interests.

\section{Ethical considerations}

Ethical issues (including plagiarism, data fabrication, double publication) have been completely observed by the authors.

\section{Funding/Support}

None

\section{References}

1. Sultanpur CM, Deepa K, Kumar SV. Comprehensive review on hbalc in diagnosis of diabetes mellitus. Int J Pharm Sci Rev Res. 2010;3:119-22.

2. Olokoba AB, Obateru OA, Olokoba LB. Type 2 diabetes mellitus: a review of current trends. Oman Med J. 2012;27:269-73. doi: 10.5001/omj.2012.68.

3. Alberti KG, Zimmet PZ. Definition, diagnosis and classification of diabetes mellitus and its complications. Part 1: diagnosis and classification of diabetes mellitus provisional report of a WHO consultation. Diabet Med. 1998;15:539-53.

4. Simon D. Epidemiological features of type 2 diabetes. Rev
Prat. 2010;60:469-73.

5. Zimmet P. The burden of type 2 diabetes mellitus: are we doing enough? Diabetes Metab. 2003;29:6S9-18. doi:10.1016/S1262-3636(03)72783-9.

6. Huisman TH, Martis EA, Dozy A. Chromatography of hemoglobin Types on carboxymethylcellulose. J Lab Clin Med. 1958;52:312-27.

7. Bookchin RM, Gallop PM. Structure of haemoglobin A1c: nature of the $\mathrm{N}$-terminal beta chain blocking group. Biochem Biophys Res Commun. 1968;32:86-93.doi: 10.1016/0006-291X(68)90430-0.

8. Rahbar S, Blumenfeld O, Ranney HM. Studies of an unusual hemoglobin in patients with diabetes mellitus. Biochem Biophys Res Commun. 1969;36:838-43. doi:10.1016/0006291X(69)90685-8.

9. Bunn HF, Haney DN, Gabbay KH, Gallop PM. Further identification of the nature and linkage of the carbohydrate in haemoglobin A1c. Biochem Biophys Res Commun. 1975;67:103-9. doi: 10.1016/0006-291X(75)90289-2.

10. Sherwani SI, Khan HA, Ekhzaimy A, Masood A, Sakharkar MK. Significance of HbAlc test in diagnosis and prognosis of diabetic patients. Biomark Insights. 2016;11:95-104. doi: 10.4137/BMI.S38440.

11. Longini IM Jr, Clark WS, Byers RH, Ward JW, Darrow WW, Lemp GF, et al. Statistical analysis of the stages of HIV infection using a Markov model. Stat Med. 1989;8:831-43. doi:10.1002/sim.4780080708.

12. Aalen OO, Farewell VT, De Angelis D, Day NE, Gill ON. A Markov model for HIV disease progression including the effect of HIV diagnosis and treatment: application to AIDS prediction in England and Wales. Stat Med. 1997;16:2191210.

13. Hendriks JC, Satten GA, van Ameijden EJ, van Druten HA, Coutinho RA, van Griensven GJ. The incubation period to AIDS in injecting drug users estimated from prevalent cohort data, accounting for death prior to an AIDS diagnosis. AIDS. 1998;12:1537-44.doi: 10.1097/00002030199812000-00017.

14. Grover G, Gadpayle AK, Swain, PK, Deka B. A multistate Markov model based on CD4 cell count for HIV/AIDS Patients on Antiretroviral Therapy (ART). Int J Stat Med Res. 2013;2:144-151.

15. Duffy SW, Day NE, Tabár L, Chen HH, Smith TC. Markov models of breast tumor progression: some age-specific results. J Natl Cancer Inst Monogr. 1997:93-7. doi: 10.1093/ jncimono/1997.22.93.

16. Putter H, van der Hage J, de Bock GH, Elgalta R, van de Velde CJ. Estimation and prediction in a multi-state model for breast cancer. Biom J. 2006;48:366-80. doi: 10.1002/ bimj.200510218.

17. Joly P, Commenges D, Helmer C, Letenneur L. A penalized likelihood approach for an illness-death model with interval-censored data: application to age-specific incidence of dementia. Biostatistics. 2002;3:433-43.doi: 10.1093/biostatistics/3.3.433.

18. Marshall G, Jones RH. Multi-state models and diabetic retinopathy. Stat Med. 199514:1975-83.

19. Srikanth P. Using Markov chains to predict the natural progression of diabetic retinopathy. Int J Ophthalmol. 2015;8:132-7. doi: 10.3980/j.issn.2222-3959.2015.01.25. 
20. Andersen PK, Hansen LS, Keiding N. Non-and semiparametric estimation of transition probabilities from censored observation of a non-homogeneous Markov process. Scand J Statist. 1991;18:153-167.

21. Grover G, Seth D, Vjala R, Swain PK. A multistate Markov model for theprogression of liver cirrhosis in the presence of various prognostic factors. Chil J Stat. 2014;5:15-27.

22. Begun A, Morbach S, Rümenapf G, Icks A. Study of disease progression and relevant risk factors in diabetic foot patients using a multistate continuous-time Markov chain model. PLoS One. 2016;11:e0147533. doi: 10.1371/journal. pone. 0147533 .

23. Chiang CL. Introduction to stochastic Processes in Biostatistics. New York: John Wiley \& Sons Inc: 1968.

24. Kalbfleisch JD, Lawless JF. The analysis of panel data under a Markov assumption. J Am Statist Assoc. 1985;80:863-71.

25. Jackson $\mathrm{CH}$. Multistate Models for Panel Data: The msm Package for R. J Statist Software. 2011;38:1-29.

Copyright $\odot 2018$ The Author(s); Published by Society of Diabetic Nephropathy Prevention. This is an open-access article distributed under the terms of the Creative Commons Attribution License (http://creativecommons.org/licenses/by/4.0), which permits unrestricted use, distribution, and reproduction in any medium, provided the original work is properly cited. 